\title{
The hemodynamic and atrial electrophysiologic consequences of chronic left atrial volume overload in a controllable canine model
}

Chawannuch Ruaengsri, MD, ${ }^{\mathrm{a}, \mathrm{b}}$ Matthew R. Schill, MD, ${ }^{\mathrm{a}}$ Timothy S. Lancaster, MD,

Ali J. Khiabani, MD, , Joshua L. Manghelli, DO, ${ }^{a}$ Daniel I. Carter, BS, ${ }^{a}$ Jason W. Greenberg, BS, ${ }^{a}$

Spencer J. Melby, MD, ${ }^{a}$ Richard B. Schuessler, PhD, ${ }^{a}$ and Ralph J. Damiano, Jr, MD

\section{ABSTRACT}

Objective: The purpose of this study was to determine the effects of chronic left atrial volume overload on atrial anatomy, hemodynamics, and electrophysiology using a titratable left ventriculoatrial shunt in a canine model.

Methods: Canines $(n=16)$ underwent implantation of a shunt between the left ventricle and the left atrium. Sham animals $(n=8)$ underwent a median sternotomy without a shunt. Atrial activation times and effective refractory periods were determined using 250-bipolar epicardial electrodes. Biatrial pressures, systemic pressures, left atrial and left ventricle diameters and volumes, atrial fibrillation inducibility, and durations were recorded at the initial and at 6-month terminal study.

Results: Baseline shunt fraction was $46 \% \pm 8 \%$. The left atrial pressure increased from $9.7 \pm 3.5 \mathrm{~mm} \mathrm{Hg}$ to $13.8 \pm 4 \mathrm{~mm} \mathrm{Hg}(P<.001)$. At the terminal study, the left atrial diameter increased from a baseline of $2.9 \pm 0.05 \mathrm{~cm}$ to $4.1 \pm 0.6 \mathrm{~cm}(P<.001)$ and left ventricular ejection fraction decreased from $64 \% \pm 1.5 \%$ to $54 \% \pm 2.7 \%$ $(P<.001)$. Induced atrial fibrillation duration (median, range) was 95 seconds (0-7200) compared with 0 seconds $(0-40)$ in the sham group $(P=.02)$. The total activation time was longer in the shunt group compared with the sham group (72 $\pm 11 \mathrm{~ms}$ vs $62 \pm 3 \mathrm{~ms}, P=.003)$. The right atrial and not left atrial effective refractory periods were shorter in the shunt compared with the sham group (right atrial effective refractory period: $156 \pm 11 \mathrm{~ms}$ vs $141 \pm 11 \mathrm{~ms}, P=.005$; left atrial effective refractory period: $142 \pm 23 \mathrm{~ms}$ vs $133 \pm 11 \mathrm{~ms}, P=.35$ ).

Conclusions: This canine model of mitral regurgitation reproduced the mechanical and electrical remodeling seen in clinical mitral regurgitation. Left atrial size increased, with a corresponding decrease in left ventricle systolic function, and an increased atrial activation times, lower effective refractory periods, and increased atrial fibrillation inducibility. This model provides a means to understand the remodeling by which mitral regurgitation causes atrial fibrillation. (J Thorac Cardiovasc Surg 2018;156:1871-9)

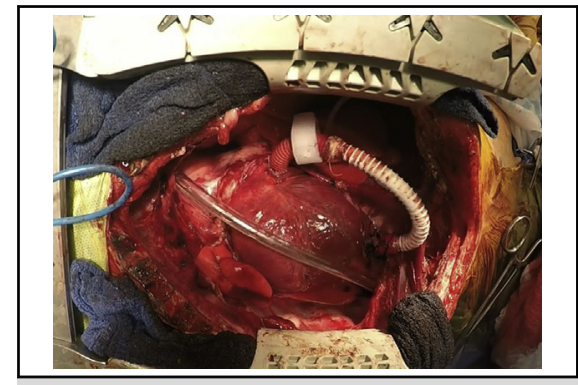

Implanted MR shunt with hydraulic occlude.

Central Message

AF occurs in up to $30 \%$ of patients with MR who are referred for surgery. This model provides a means to extrapolate the dynamic proarrhythmic remodeling by which MR causes AF.

\section{Perspective}

This animal study will help surgeons to extrapolate the time course of mechanical and electrical remodeling, which may inform the timing of surgical intervention for $\mathrm{AF}$ and MR. Better understanding of the pathogenesis of $\mathrm{AF}$ in MR will improve surgeons' knowledge and inform future clinical investigation and intervention on this topic.

See Editorial Commentary page 1880.

See Editorial page 1869.

\footnotetext{
From the a Division of Cardiothoracic Surgery, Department of Surgery, Washington University School of Medicine, Barnes-Jewish Hospital, St Louis, Mo; and ${ }^{\mathrm{b}}$ Division of Cardiothoracic Surgery, Department of Surgery, Mahidol University, Ramathibodi Hospital, Bangkok, Thailand.

Sources of Funding: M.R.S., T.S.L., A.J.K., and J.L.M. are supported by T32-HL007776. R.L.D. Jr, and R.B.S. are supported by R01-HL032257 and the Barnes Jewish Foundation. S.J.M. is supported by Veterans Administrations Merit I01 CX001526.

Received for publication Jan 10, 2018; revisions received May 18, 2018; accepted for publication May 21, 2018.

Address for reprints: Ralph J. Damiano, Jr, MD, Division of Cardiothoracic Surgery, Washington University School of Medicine, Barnes-Jewish Hospital, Campus Box 8234, 660 S Euclid Ave, St Louis, MO 63110 (E-mail: damianor@wustl.edu). $0022-5223 / \$ 36.00$

Copyright (C) 2018 Published by Elsevier Inc. on behalf of The American Association for Thoracic Surgery

https://doi.org/10.1016/j.jtcvs.2018.05.078
}

Mitral regurgitation (MR) is the most common valvular disease in the United States with a prevalence of 2 to 2.5 million, and the incidence is expected to double by the

Uf Scanning this QR code will
take you to a supplemental ap-
$\begin{aligned} & \text { pendix and video for this } \\ & \text { article. }\end{aligned}$




$$
\begin{aligned}
& \text { Abbreviations and Acronyms } \\
& \mathrm{ACT}=\text { activated clotting time } \\
& \mathrm{AF} \quad=\text { atrial fibrillation } \\
& \text { ERP = effective refractory period } \\
& \text { LA }=\text { left atrium } \\
& \text { LAA = left atrial appendage } \\
& \text { LAERP }=\text { left atrial effective refractory period } \\
& \mathrm{LV} \quad=\text { left ventricle } \\
& \text { MR = mitral regurgitation } \\
& \mathrm{MV}=\text { mitral valve } \\
& \text { PTFE = polytetrafluoroethylene } \\
& \text { PV = pulmonary vein } \\
& \mathrm{RA}=\text { right atrium } \\
& \text { RAERP }=\text { right atrial effective refractory period } \\
& \text { TEE }=\text { transesophageal echocardiography }
\end{aligned}
$$

year 2030. ${ }^{1}$ Atrial fibrillation (AF) has been found to be present in up to $30 \%$ of patients presenting for mitral valve (MV) repair or replacement, and it has a significant negative impact on late survival. ${ }^{2}$ Patients with MV disease form the largest group of patients in virtually all surgical series of $\mathrm{AF}$ ablation. ${ }^{3}$ However, there have been few experimental studies defining the mechanisms and substrates responsible for $\mathrm{AF}$ in this population. A better understanding of both the electrophysiologic mechanisms of $\mathrm{AF}$ in patients with $\mathrm{MV}$ disease and the underlying electrical and anatomic remodeling responsible for this arrhythmia is essential in the development of a more rational surgical ablation strategy to restore normal sinus rhythm in this group of patients. The lack of adequate and reversible experimental model of chronic MR has hampered progress in the mechanistic understanding of AF in these patients. This knowledge gap has resulted in great controversy on the appropriate surgical ablation strategy in these patients, with surgeons advocating for pulmonary vein (PV) isolation alone, left atrial (LA), or biatrial lesion sets. ${ }^{4}$ The most complete lesion set is the Cox-Maze procedure involving a complex set of biatrial ablation lines. ${ }^{5}$ Unfortunately, even this lesion set fails to eliminate $\mathrm{AF}$ in $30 \%$ or more of patients at late follow-up. ${ }^{6}$

Two models have been developed to study pathophysiology of MR and to test potential medical and surgical treatments. However, they have all had significant shortcomings. ${ }^{7-10}$ A canine chordae cut model has been the most widely studied. ${ }^{7,10-13}$ This procedure can be done via a surgical (ie, an open chest) or percutaneous approach (ie, closed chest). In the open chest approach, a Cope biopsy needle was inserted into the PV in an attempt to rupture the chordae. In the closed chest or transarterial approach, under fluoroscopic or transesophageal echocardiography (TEE) guidance, a biopsy forceps catheter was placed in the left ventricle (LV) by means of an introducer inserted into the carotid artery to cut or damage the MV chordae and thus produce MR. The procedure can be repeated to increase the severity of MR. ${ }^{12}$ The disadvantage of this model is that it produced an uncontrollable amount of MR that could not be reversed. Another large animal model that has been described is a left ventriculoatrial shunt. This model was introduced by Braunwald and colleagues ${ }^{14}$ and further refined by Rankin and colleagues.' Braunwald and colleagues studied the acute hemodynamic effects of MR, and Rankin and colleagues investigated the effect of chronic MR and shunt occlusion on LV function. Atrial physiology was not investigated in these studies. Unfortunately, this model has not been used over the last several decades because of its technical difficulty and problems with graft patency.

The aim of the present study was to develop a chronic canine model of MR, using a modified ventriculoatrial shunt in which the degree of regurgitation can be precisely controlled, and use this to characterize the structural, electrical, and mechanical remodeling of the atria.

\section{MATERIALS AND METHODS \\ Shunt Design}

The first challenge was to create a shunt that could simulate severe MR and would remain chronically patent. After a number of iterations, a novel shunt design was developed that was composed of 3 components (Figures 1 and 2). ${ }^{1}$ A $2.5-\mathrm{cm}$-long straight tip of a plastic venous cannula, with a 10-mm outer diameter, was used to cannulate the LV apex. ${ }^{2}$ A composite graft was developed that consisted of a $10-\mathrm{mm}$ bovine collagenimpregnated knitted polyester (MAQUET, Rastatt, Germany) joined to ${ }^{3}$ an 8-mm reinforced polytetrafluoroethylene (PTFE) graft (WL Gore and Associates, Inc, Newark, Del) connected by a continuous running of CV-6, TTc-9-PTFE suture (WL Gore and Associates, Inc), with needle holes filled with Epoxy glue. The composite graft was made with the reinforced PTFE to provide kink and compression resistance. Because the ultrasonic flow probe does not record flow through PTFE grafts, a section of the polyester graft was used on the atrial end. To avoid thromboembolism, the inner side of the plastic cannula was lined with the end of reinforced PTFE graft inserted through the lumen of the plastic

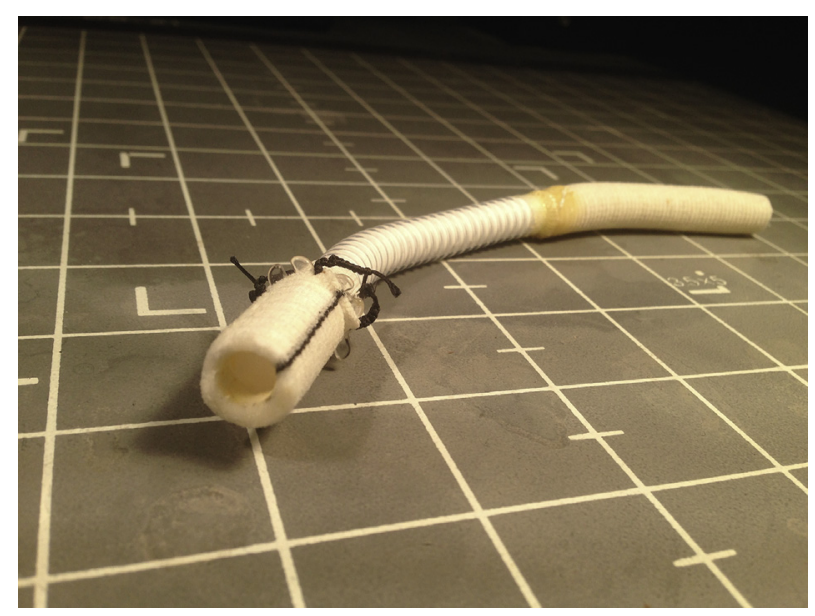

FIGURE 1. The final iteration of the ventriculoatrial shunt. 


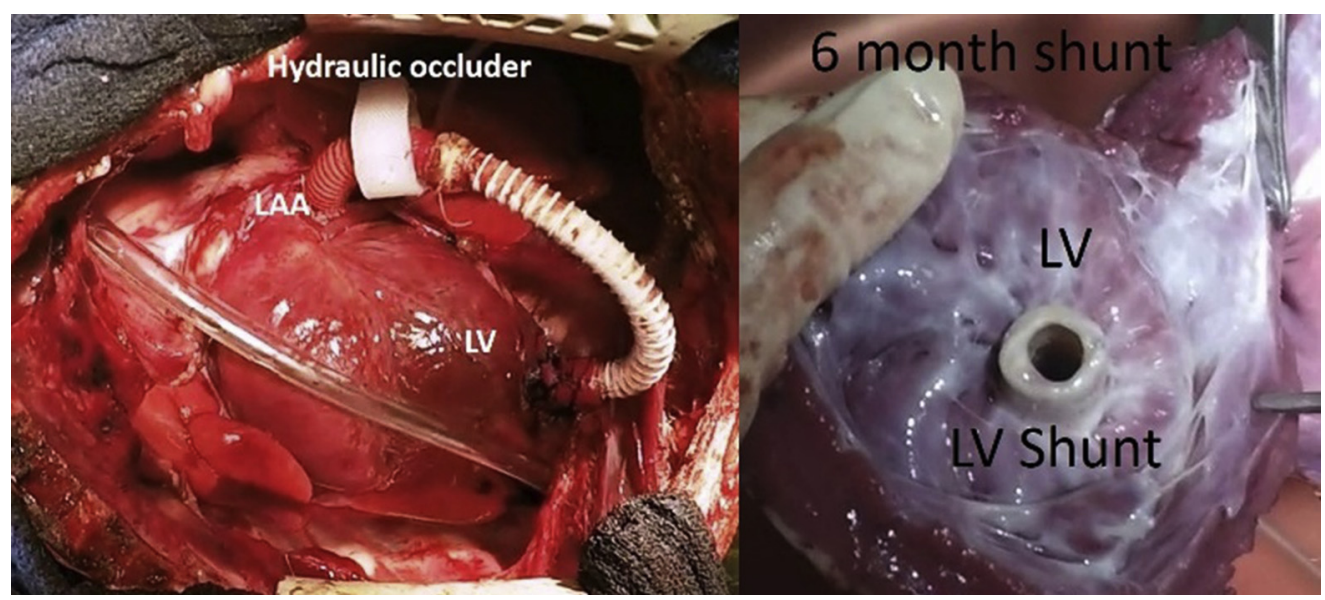

FIGURE 2. Implanted shunt with hydraulic occluder (left). At 6 months the shunt in the LV apex showing a smooth layer of endothelium (right). $L A A$, Left atrial appendage; $L V$, left ventricle.

cannula. This was secured to the outer surface covered with a piece of polyester graft covering the outer surface of the plastic cannula. The graft was 12 to $15 \mathrm{~cm}$ long. For the shunt to be reversible and titratable, a hydraulic occluder was placed around the shunt to allow us to titrate the shunt flow via a subcutaneous port.

\section{Surgical Technique}

The study protocol was approved by the Washington University School of Medicine Animal Studies Committee. All animals involved in this study received humane care in compliance with the 2011 Guide for the Care and Used of Laboratory Animals prepared by the National Academy of Science and published by National Institutes of Health. A total of 24 mongrel canines weighing 23 to $29.5 \mathrm{~kg}$ were used in this study. Dogs were intubated and mechanically ventilated. Anesthesia was maintained using $1 \%$ to $3 \%$ inhaled isoflurane. Monitoring included a limb-lead electrocardiogram and pulse oximetry. An esophageal temperature probe and heating pad were used to keep the temperature greater than $37.5^{\circ} \mathrm{C}$. Through a subinguinal incision, the femoral artery and vein were used for cannulation to monitor arterial and central venous pressure, respectively. A 7F catheter was inserted through a femoral venous sheath to the level of right atrium (RA) to monitor central venous pressure. Dogs received normal saline for the maintenance fluid. Arterial blood gas was drawn every 30 minutes to determine oxygen tension, acid-base balance, and electrolyte levels that were normalized as needed. Activated clotting time (ACT) was also checked every 30 minutes. Phenylephrine was initiated for systolic blood pressure less than $70 \mathrm{~mm} \mathrm{Hg}$ and aggressively weaned.

\section{Implantation of the Shunt}

After the dogs were anesthetized, a median sternotomy was performed and pericardium was opened. A 16 - to 20-mm flow probe was connected to a TS420 Perivascular Flow module (Transonic, Ithaca, NY) and placed around the ascending aorta to determine cardiac output. Before shunt implantation, $150 \mathrm{U} / \mathrm{kg}$ of heparin was given intravenously, with an ACT goal of greater than 350 seconds. After full heparinization, shunt dogs $(\mathrm{n}=16)$ underwent implantation of a ventriculoatrial shunt between the LV apex and left atrial appendage (LAA). Throughout the procedure, ACT was maintained at or more than 350 seconds. Two double pledgeted 3-0 polypropylene sutures were placed at the LV apex. The plastic cannula end of the shunt was inserted into the LV apex using a Seldinger technique. The tip of the LAA was amputated, resulting in a 1.5- to 2-cm opening. The end of the polyester graft was sutured to the LAA using a continuous running 5-0 polypropylene suture. The graft was de-aired using a 24-gauge needle. A 12-mm flow probe, calibrated to shunt size and material, was placed around the shunt to determine shunt flow. An inflatable saline occlusion band was fixed at the collapsible portion of the graft (Figure 2, A). Shunt flow was titrated to a shunt fraction of $40 \%$ to $50 \%$ of cardiac output using a saline occlusion balloon. The port attached to the band was tunneled and secured in a subcutaneous pocket on the back of the dog. The pericardium was reapproximated, and a chest tube was placed for drainage and left for 2 to 3 days. Details of operative procedure are described in Video 1. Sham dogs $(n=8)$ underwent a "sham procedure," consisting of a purse-string suture at the LV apex and amputation of the LAA without the implantation of the shunt. All dogs received pain medication and antibiotics. Shunt dogs received $5 \mathrm{mg} / \mathrm{kg}$ of aspirin daily for the duration of the study. Dogs were followed for up to 6 months.

\section{Transesophageal Echocardiography}

TEE (M-Turbo with a TEE $\times 8-3 \mathrm{MHz}$ probe Sonosite, Bothell, Wash) was used to monitor LA diameter and volume, LV ejection fraction, and shunt patency at baseline and monthly. Atrial volumes and diameters were measured in accordance with the 2015 American Society of Echocardiography's guidelines for chamber quantification and using Simpson's rule. ${ }^{15}$ LA diameter was recorded as distance between the posterior LA wall and MV annulus (Figure 3). Both volumes and diameters were measured at the end ventricular systole, just before MV opening. Shunt patency was examined by color Doppler signal visualization (Figure 3,C). LV volumes were measured at the end systole and diastole to determine $\mathrm{LV}$ ejection fraction.

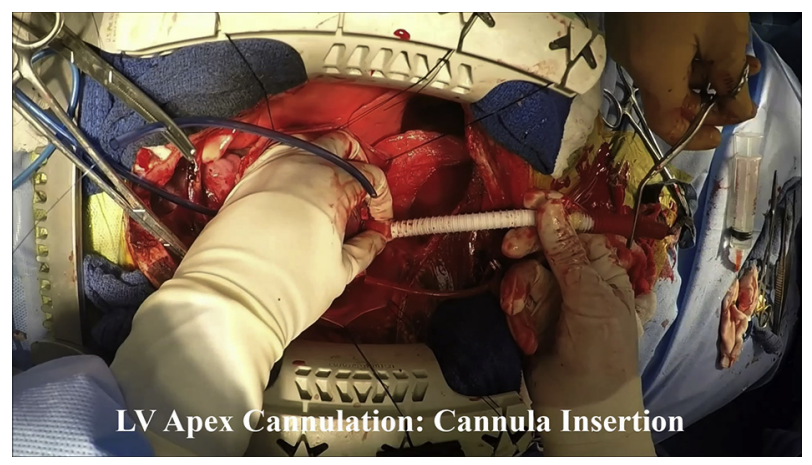

VIDEO 1. Video clip of MR shunt implantation. Video available at: https://www.jtcvs.org/article/S0022-5223(18)31508-3/fulltext. 


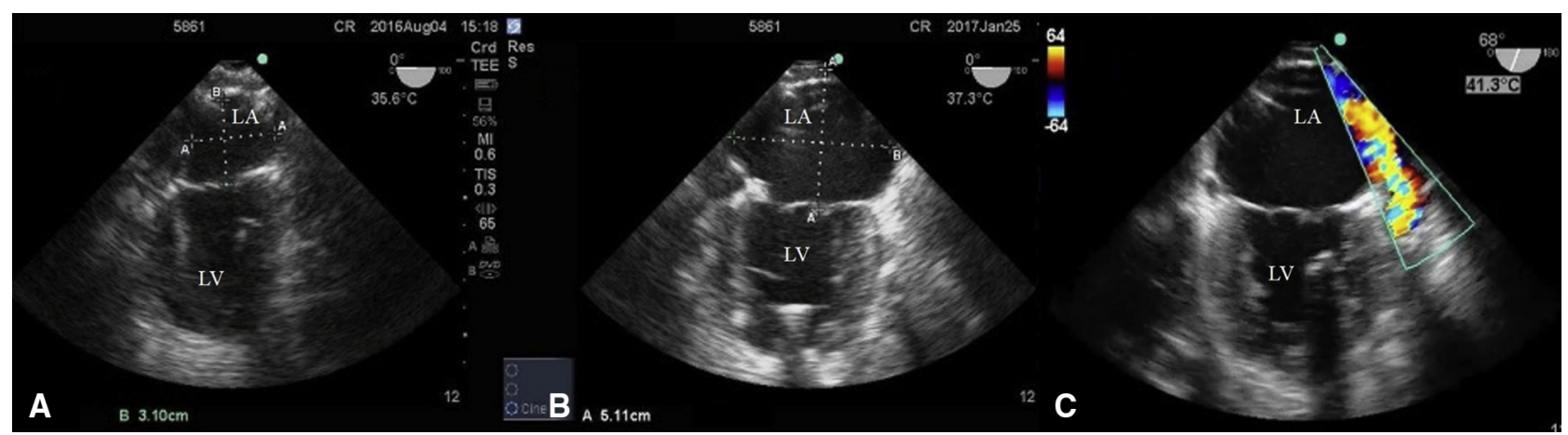

FIGURE 3. Transesophageal echocardiogram before shunt implant (A) and at 6 months (B and C). In comparing (A and B), the shunt animal demonstrated marked LA dilatation. C, Doppler flow through the shunt. $L A$, Left atrium; $L V$, left ventricle.

\section{Electrophysiology Study}

To record electrograms from the atria, 3 silastic form-fitting templates with a total of 250-bipolar electrodes were secured to the atrial epicardium. The intraelectrode distance was $5 \mathrm{~mm}$. Data were recorded during normal sinus rhythm, atrial pacing, and any induced arrhythmias at a gain of 500 with a frequency response of 50 to $1000 \mathrm{~Hz}$ and was digitized at $2000 \mathrm{~Hz}$. ERPs were determined at 6 epicardial sites (4 LA, 2 RA) using extrastimulus technique, with 8 $\mathrm{S} 1 \mathrm{~s}$ at a basic cycle length of $300 \mathrm{~ms}$, followed by an S2 decremented by $5 \mathrm{~ms}$ until loss of capture. Induction of AF was done by burst pacing from site of lowest ERP, at a paced cycled length $10 \mathrm{~ms}$ shorter than the lowest ERP. This was repeated 4 times. AF greater than 30 seconds was considered sustained. The sum of all 4 attempts was used as the total duration of AF. Activation times were determined by the maximum amplitude of the bipolar electrograms. From the activation maps, total activation time was determined. Conduction heterogeneity was calculated as the distance-normalized maximum phase difference between each point and its neighbors. ${ }^{16}$

TABLE 1. Sham versus shunt

\begin{tabular}{|c|c|c|c|c|c|c|}
\hline & \multicolumn{2}{|c|}{ Control } & \multirow[b]{2}{*}{$\boldsymbol{P}$} & \multicolumn{2}{|c|}{6 months } & \multirow[b]{2}{*}{$\boldsymbol{P}$} \\
\hline & Sham & Shunt & & Sham & Shunt & \\
\hline \multicolumn{7}{|l|}{ Hemodynamics } \\
\hline Weight $(\mathrm{kg})$ & $25 \pm 1.3$ & $25 \pm 1.9$ & .93 & $27 \pm 3.2$ & $26 \pm 4.4$ & .6 \\
\hline Systolic blood pressure $(\mathrm{mm} \mathrm{Hg})$ & $88 \pm 14$ & $92 \pm 12$ & .43 & $75 \pm 13$ & $96 \pm 8$ & .004 \\
\hline Diastolic blood pressure (mm $\mathrm{Hg}$ ) & $44 \pm 7$ & $46 \pm 9$ & .58 & $36 \pm 8$ & $50 \pm 9$ & .003 \\
\hline Cardiac output $(\mathrm{L} / \mathrm{m})$ & $2.6 \pm 0.86$ & $2.4 \pm 0.52$ & .54 & $2.6 \pm 0.8$ & $2.2 \pm 0.5$ & .1 \\
\hline Max LAP (mm Hg) & $9.8 \pm 1.6$ & $9.7 \pm 3.5$ & .9 & $9.8 \pm 1.7$ & $13.8 \pm 4$ & .014 \\
\hline Min LAP (mm Hg) & $5.4 \pm 1.6$ & $5.7 \pm 3.8$ & .78 & $6.3 \pm 1.9$ & $7.2 \pm 3.7$ & .471 \\
\hline Max RAP (mm Hg) & $5.1 \pm 2.2$ & $4.9 \pm 1.7$ & .77 & $5.6 \pm 1.3$ & $6.8 \pm 1.7$ & .06 \\
\hline Min RAP (mm Hg) & $3.3 \pm 2.7$ & $2.9 \pm 1.9$ & .32 & $3.2 \pm 1.4$ & $3.8 \pm 1.1$ & .7 \\
\hline CVP (mm Hg) & $2.5 \pm 0.8$ & $2.8 \pm 1.3$ & .47 & $2.4 \pm 1.7$ & $3.7 \pm 2.0$ & .16 \\
\hline LV ESV $(\mathrm{mL})$ & $18 \pm 1.1$ & $18 \pm 1.1$ & .85 & $17 \pm 1.8$ & $30 \pm 4.8$ & $<.001$ \\
\hline LV EDV (mL) & $48 \pm 2.9$ & $48 \pm 2.7$ & .95 & $47 \pm 3.9$ & $68 \pm 6.5$ & $<.001$ \\
\hline LV EF $(\%)$ & $63 \pm 1.0$ & $64 \pm 1.5$ & .29 & $65 \pm 1.0$ & $54 \pm 2.7$ & $<.001$ \\
\hline $\mathrm{LAD}(\mathrm{cm})$ & $3.0 \pm 0.06$ & $2.9 \pm 0.05$ & .3 & $3.3 \pm 0.08$ & $4.1 \pm 0.6$ & $<.001$ \\
\hline LAV (mL) & $20 \pm 0.4$ & $21 \pm 1.6$ & .27 & $22 \pm 0.4$ & $34 \pm 10$ & .002 \\
\hline \multicolumn{7}{|l|}{ Electrophysiology } \\
\hline Heart rate (beats/min) & $106 \pm 13$ & $115 \pm 12$ & .12 & $115 \pm 20$ & $126 \pm 24$ & .4 \\
\hline Total activation time (ms) & $61 \pm 5$ & $65 \pm 7$ & .43 & $62 \pm 3$ & $72 \pm 11$ & .008 \\
\hline RA inhomogeneity $(\mathrm{ms} / \mathrm{mm})$ & $2.6 \pm 1.3$ & $2.5 \pm 0.7$ & .8 & $1.8 \pm 0.7$ & $2.9 \pm 0.9$ & .004 \\
\hline LA inhomogeneity (ms/mm) & $1.5 \pm 0.34$ & $1.7 \pm 0.3$ & .34 & $1.6 \pm 0.6$ & $2.2 \pm 0.7$ & .04 \\
\hline RA-ERP (ms) & $134 \pm 10$ & $141 \pm 8$ & .09 & $156 \pm 11$ & $141 \pm 11$ & .005 \\
\hline LA-ERP (ms) & $131 \pm 10$ & $137 \pm 8$ & .16 & $142 \pm 23$ & $133 \pm 11$ & .35 \\
\hline Dispersion of ERP (ms) & $45 \pm 15$ & $43 \pm 17$ & .75 & $56 \pm 21$ & $49 \pm 23$ & .42 \\
\hline AF duration (s) median (range) & $0(0-137)$ & $9(0-180)$ & .1 & $0(0-40)$ & $95(0-7200)$ & .02 \\
\hline $\mathrm{AF}>30 \mathrm{~s}(\%)$ & 12 & 18 & .9 & 0 & 62 & .006 \\
\hline
\end{tabular}

Comparisons between sham and shunt groups were made using the analysis of variance model. To compare AF duration, a Mann-Whitney $U$ test was used and to compare $\mathrm{AF}$ $>30$ seconds, a Fisher exact test was used. $L A P$, left atrial pressure; $R A P$, right atrial pressure; $C V P$, central venous pressure; $L V E S V$, left ventricle end-systolic volume; $L V E D V$, left ventricle end-diastolic volume; $L V E F$, left ventricle ejection fraction; $L A D$, left atrial diameter; $L A V$, left atrial volume; $R A$, right atrium; $L A$, left atrial; $E R P$, effective refractory period; $A F$, atrial fibrillation. 


\begin{tabular}{|c|c|c|c|c|c|c|}
\hline & \multicolumn{2}{|c|}{ Sham } & \multirow[b]{2}{*}{$\boldsymbol{P}$} & \multicolumn{2}{|c|}{ Shunt } & \multirow[b]{2}{*}{$\boldsymbol{P}$} \\
\hline & Control & 6 months & & Control & 6 months & \\
\hline \multicolumn{7}{|l|}{ Hemodynamics } \\
\hline Systolic blood pressure (mm Hg) & $88 \pm 14$ & $75 \pm 13$ & .11 & $92 \pm 12$ & $96 \pm 8$ & .43 \\
\hline Diastolic blood pressure $(\mathrm{mm} \mathrm{Hg})$ & $44 \pm 7$ & $36 \pm 8$ & .16 & $46 \pm 9$ & $50 \pm 9$ & .06 \\
\hline Cardiac output (L/m) & $2.6 \pm 0.86$ & $2.6 \pm 0.8$ & .12 & $2.4 \pm 0.52$ & $2.2 \pm 0.5$ & .89 \\
\hline Shunt flow $(\mathrm{L} / \mathrm{m})$ & NA & NA & & $1.9 \pm 0.6$ & $1.2 \pm 0.6$ & .002 \\
\hline Shunt fraction $(\%)$ & NA & NA & & $46 \pm 0.08$ & $34 \pm 0.1$ & $<.001$ \\
\hline Max LAP (mm Hg) & $9.8 \pm 1.6$ & $9.8 \pm 1.7$ & .86 & $9.7 \pm 3.5$ & $13.8 \pm 4$ & .004 \\
\hline Min LAP (mm Hg) & $5.4 \pm 1.6$ & $6.3 \pm 1.9$ & .08 & $5.7 \pm 3.8$ & $7.2 \pm 3.7$ & .05 \\
\hline Max RAP (mm Hg) & $5.1 \pm 2.2$ & $5.6 \pm 1.3$ & .59 & $4.9 \pm 1.7$ & $6.8 \pm 1.7$ & .009 \\
\hline Min RAP (mm Hg) & $3.3 \pm 2.7$ & $3.2 \pm 1.4$ & .95 & $2.9 \pm 1.9$ & $3.8 \pm 1.1$ & .21 \\
\hline CVP (mm Hg) & $2.5 \pm 0.8$ & $2.4 \pm 1.7$ & .95 & $2.8 \pm 1.3$ & $3.7 \pm 2.0$ & .18 \\
\hline LV ESV (mL) & $18 \pm 1.1$ & $17 \pm 1.8$ & .19 & $18 \pm 1.1$ & $30 \pm 4.8$ & $<.001$ \\
\hline LV EDV (mL) & $48 \pm 2.9$ & $47 \pm 3.9$ & .67 & $48 \pm 2.7$ & $68 \pm 6.5$ & $<.001$ \\
\hline LV EF $(\%)$ & $63 \pm 1.0$ & $65 \pm 1.0$ & .14 & $64 \pm 1.5$ & $54 \pm 2.7$ & $<.001$ \\
\hline $\mathrm{LAD}(\mathrm{cm})$ & $3.0 \pm 0.06$ & $3.3 \pm 0.08$ & .001 & $2.9 \pm 0.05$ & $4.1 \pm 0.6$ & $<.001$ \\
\hline LAV (mL) & $20 \pm 0.4$ & $22 \pm 0.4$ & $<.001$ & $21 \pm 1.6$ & $34 \pm 10$ & $<.001$ \\
\hline \multicolumn{7}{|l|}{ Electrophysiology } \\
\hline Heart rate (beats/min) & $106 \pm 13$ & $115 \pm 20$ & .18 & $115 \pm 12$ & $126 \pm 24$ & .47 \\
\hline Total activation time (ms) & $61 \pm 5$ & $62 \pm 3$ & .59 & $65 \pm 7$ & $72 \pm 11$ & .006 \\
\hline RA inhomogeneity (ms/mm) & $2.6 \pm 1.3$ & $1.8 \pm 0.7$ & .09 & $2.5 \pm 0.7$ & $2.9 \pm 0.9$ & .12 \\
\hline LA inhomogeneity $(\mathrm{ms} / \mathrm{mm})$ & $1.5 \pm 0.34$ & $1.6 \pm 0.6$ & .91 & $1.7 \pm 0.3$ & $2.2 \pm 0.7$ & .02 \\
\hline RA ERP (ms) & $134 \pm 10$ & $156 \pm 11$ & .013 & $141 \pm 8$ & $141 \pm 11$ & .92 \\
\hline LA ERP (ms) & $131 \pm 10$ & $142 \pm 23$ & .003 & $137 \pm 8$ & $133 \pm 11$ & .304 \\
\hline Dispersion of ERP (ms) & $45 \pm 15$ & $56 \pm 21$ & .05 & $43 \pm 17$ & $49 \pm 23$ & .4 \\
\hline AF duration (s) median (range) & $0(0-137)$ & $0(0-40)$ & .91 & $9(0-180)$ & $95(0-7200)$ & .015 \\
\hline $\mathrm{AF}>30 \mathrm{~s}(\%)$ & 12 & 0 & .69 & 18 & 62 & .01 \\
\hline
\end{tabular}

Comparisons between the control and 6-month data were made using a repeated-measures analysis of variance. $L A P$, left atrial pressure; $R A P$, right atrial pressure; $C V P$, central venous pressure; $L V E S V$, left ventricle end-systolic volume; $L V E D V$, left ventricle end-diastolic volume; $L V E F$, left ventricle ejection fraction; $L A D$, left atrial diameter; $L A V$, left atrial volume; $R A$, right atrium; $L A$, left atrial; $E R P$, effective refractory period; $A F$, atrial fibrillation.

\section{Histology}

At the end of each study, the heart was removed and atrial biopsies were taken from both the RA and LA appendages, all $4 \mathrm{PVs}$, the posterior inferior LA, the posterior RA free wall, and the anterior superior LA. The specimens were fixed in $10 \%$ formalin for 24 to 48 hours, stored in $70 \%$ ethanol, embedded in paraffin, and stained with Masson's trichrome. Bright-field microscopy was performed at $40 \times$ magnification. Fibrosis was quantified by comparing the number of red and blue pixels in each image ${ }^{17}$ ( $\%$ fibrosis $=$ number of blue pixels/number of red and blue pixels).

\section{Statistical Analysis}

A power analysis was done to calculate sample size using $G^{*}$ power 3.1.9.2. (Appendix). Continuous variables were expressed as the mean \pm standard deviation. Non-normally distributed data, as determined from the Shapiro-Wilks test, were expressed as median and range. Categoric variables were expressed as frequencies and percentages with outcomes compared using the Fisher exact test. A 1-way analysis of variance was used to compare the sham versus shunt groups (Table 1), and a repeated-measures analysis of variance was done to compare control versus 6-month data (Table 2). Mann-Whitney $U$ test was used for data not normally distributed (AF duration). All data analyses were performed using SYSTAT 13 software (SYSTAT Software, Inc, Chicago, Ill).

\section{RESULTS}

During the initial development of the shunt, 2 animals were studied for 2 months to assess the shunt design. Two other animals had strokes and did not have terminal studies; 1 had a kink in the shunt, and 1 had a flaw in the construction of the shunt. Both had thrombus formations that resulted in the strokes. One other dog was euthanized at 5 months because of gastrointestinal and systemic infection. These 5 animals were excluded from the data analysis. A total of 11 shunts and 8 shams were included in final data analysis.

\section{Hemodynamic Results}

At 6 months, the final shunt design showed no signs of a clot and was covered with a smooth endothelial layer (Figure 2, right). At baseline, there were no differences between the sham and shunt groups in any of the hemodynamic or electrophysiologic variables (Tables 1 and 2). Shunt fraction was $46 \% \pm 8 \%$ at baseline and $34 \% \pm 10 \%$ at terminal study. In the shunt group at 6 months, maximum LA pressure increased from $10 \pm 3.5 \mathrm{~mm} \mathrm{Hg}$ to $14 \pm 4 \mathrm{~mm} \mathrm{Hg}(P=.004)$. Maximum RA pressure was also increased at 6 months in the shunt group $(4.9 \pm 1.7 \mathrm{~mm} \mathrm{Hg}$ vs $6.8 \pm 1.7 \mathrm{~mm} \mathrm{Hg}, P=.009)$. In contrast, RA and LA pressures were unchanged in the sham group. At 6 months, the LA diameters and LA 


\section{LA Volume}

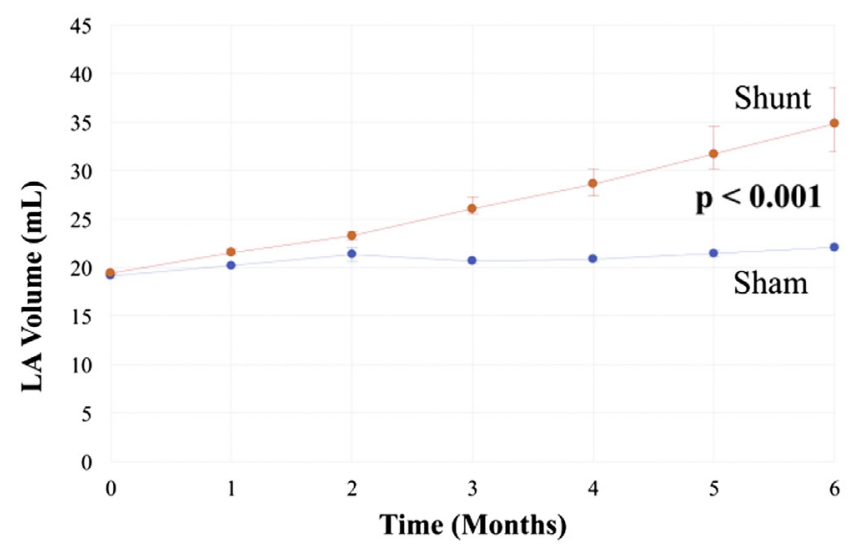

LV Ejection Fraction

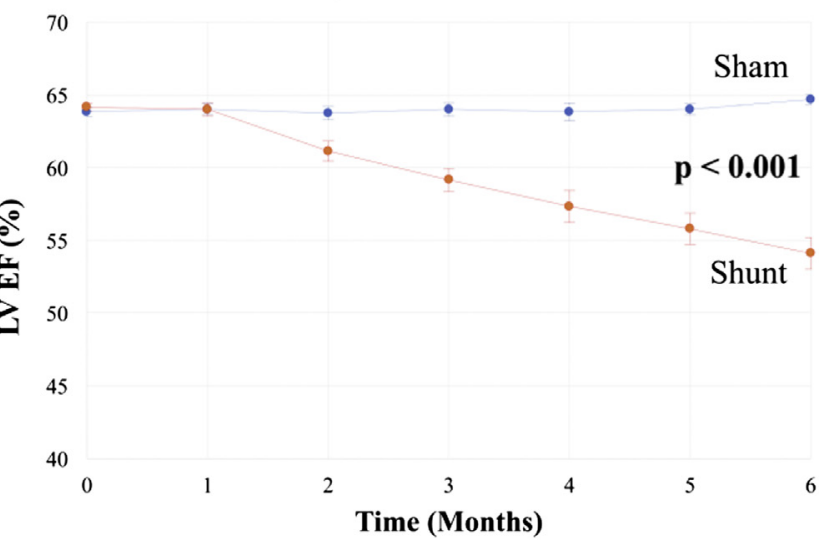

FIGURE 4. LA volume and LV ejection fraction in the sham (blue) and shunt dogs (red) over 6 months. $L A$, Left atrium; $L V$, left ventricle.

volumes increased to $141 \%$ and $168 \%$ of control, respectively (Figure 4, $P<.001$ ). LV ejection fraction decreased from a baseline of $65 \% \pm 2 \%$ to $54 \% \pm 3 \%$ $(P<.001)$ (Figure 4). There were no differences in the animals' weight between groups preoperatively $(P=.93)$ or postoperatively $(P=.60)$ (Tables 1 and 2 ).

\section{Electrophysiologic Results}

At 6 months, induced total AF duration (median, range) was 95 seconds (0-7200) in the shunt group compared with 0 seconds $(0-40)$ in the sham group $(P=.02)$. In the shunt dogs, $62 \%$ had at least 1 episode of AF of 4 attempts lasting 30 seconds or longer, whereas there were no sustained episodes of AF in the sham group. Total atrial activation time was longer in the shunt group than in the sham group ( $72 \pm 11 \mathrm{~ms}$ vs $62 \pm 3 \mathrm{~ms}, P=.003)$ at 6 months (Figure 5). The inhomogeneity of conduction in the shunt animals was greater in the RA $(1.8 \pm 0.7$ vs $2.9 \pm 0.9$, $P=.003)$ and the LA $(1.6 \pm 0.6$ vs $2.2 \pm 0.7, P=.04)$ when compared with the sham animals. The average right atrial effective refractory periods (RAERPs), but not the left atrial effective refractory periods (LAERPs), were shorter in the shunt group compared with the sham group (RAERP: $141 \pm 11 \mathrm{~ms}$ vs $156 \pm 11 \mathrm{~ms}, P=.005$; LAERP: $133 \pm 11 \mathrm{~ms}$ vs $142 \pm 23 \mathrm{~ms}, P=.35$ ). This was due to increase in the ERP in the sham group at 6 months, with no change in the shunt group. Duration of AF was highly correlated with LA volume $(\mathrm{r}=0.83, P<.001)$ and diameter $(P=.70, P=.001)$. No other variables (Tables 1 and 2) correlated with duration of induced AF.

\section{Histologic Results}

Atrial fibrosis was increased in the shunt compared with the sham animals. Tissue for fibrosis analysis was sampled at 9 different sites in the atrium (Figures 6 and 7). Overall, the shunt groups had a higher percentage of fibrosis (shunt: $5.8 \% \pm 1.2 \%$ vs sham: $4.8 \% \pm 0.6 \%, P=.014)$. Percent fibrosis at the left inferior PV regions was significantly higher in the shunt group (shunt: shunt $11.4 \% \pm 6.6 \%$ vs sham: $6.6 \% \pm 2.1 \%, P=.035)$, whereas fibrosis in other

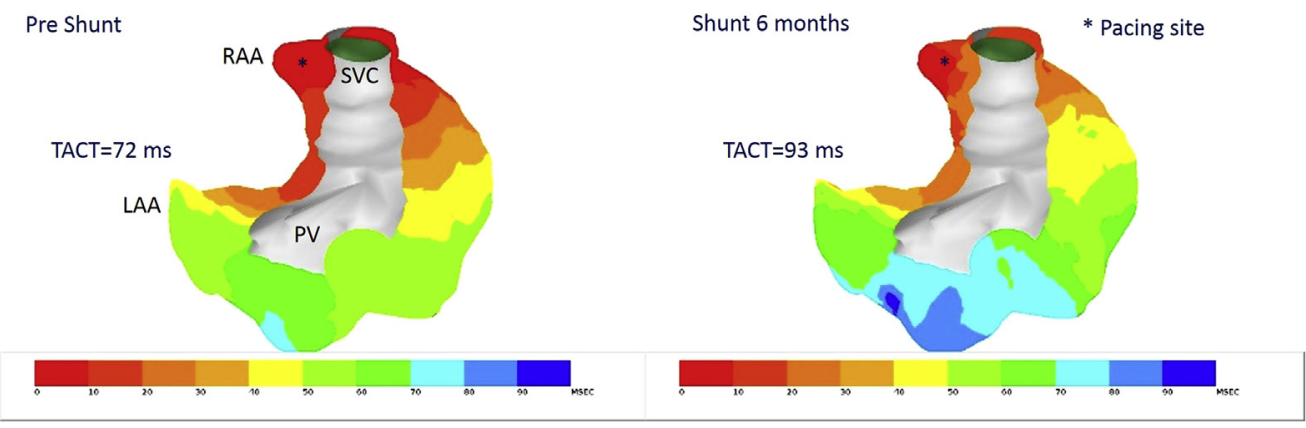

FIGURE 5. Activation map during right atrial appendage pacing, preshunt (left) and at 6 months (right). Total atrial conduction time at 6 months is longer and more inhomogeneous. TACT, Total atrial conduction time; $L A A$, left atrial appendage; $R A A$, right atrial appendage; $P V$, pulmonary vein; $S V C$, superior vena cava. 

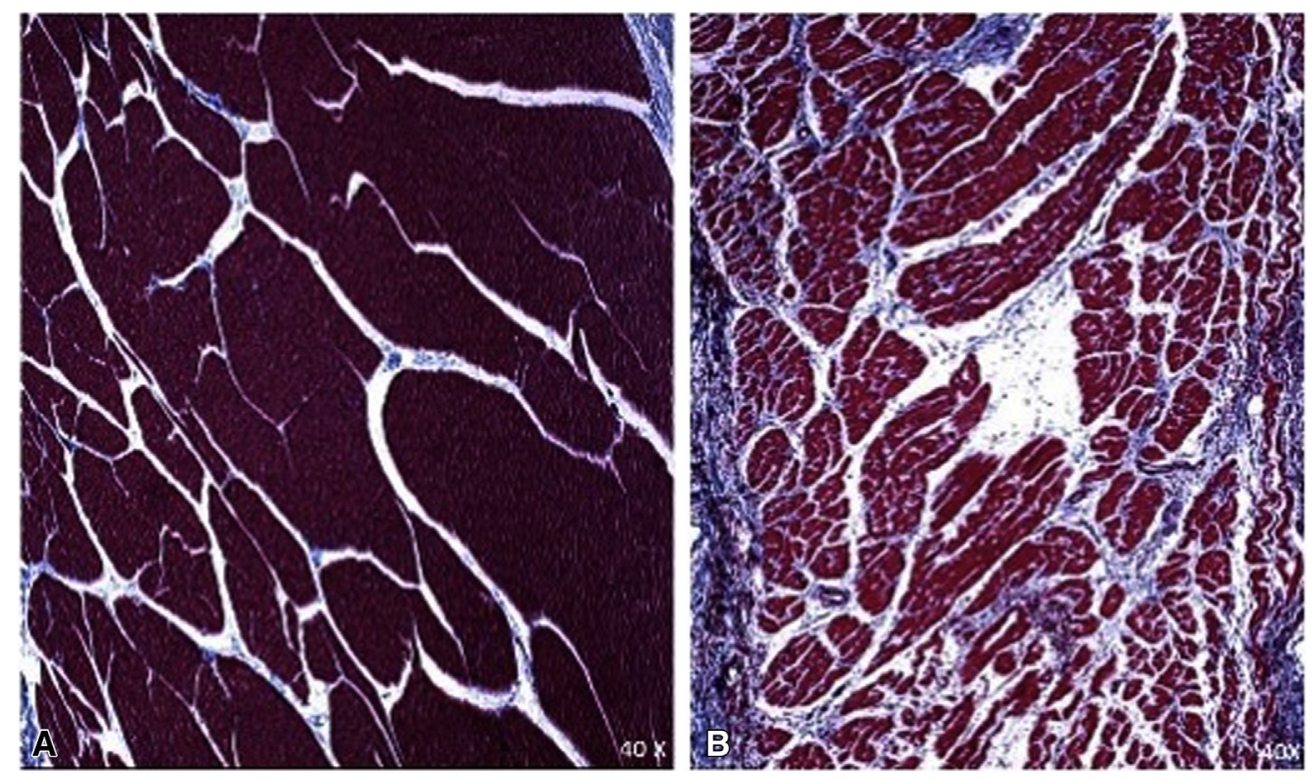

FIGURE 6. Example trichrome section from the LA near the left inferior PV in sham (A) and shunt (B).

regions was equivalent (eg, left anterior LA: sham: $3.3 \% \pm 1.6 \%$ vs shunt: $2.9 \% \pm 0.8 \%, P=.8$ ). Although the overall magnitude amount of fibrosis was not very different between the sham and shunt groups, there was a broader range and inhomogeneity in fibrosis in the LA in the shunt group, ranging from $1.3 \%$ to $11.4 \%$ in different areas of the LA (range $10.1 \%$ ), whereas the sham group only ranged from $2.7 \%$ to $6.6 \%$ (range $3.9 \%$ ).

\section{DISCUSSION}

This novel shunt model of LA volume overload replicated the clinical phenotype of MR, showing similar structural and functional changes in the LA and LV as observed in humans, as well as an increased vulnerability to induced AF. Like the chordae cut model, none of the animals had spontaneous AF. ${ }^{12,13,18}$ The time course for development of LA enlargement was different from previously published animal studies using the chordae cut model, which showed a rapid increase in LA size, which plateaued at 2 to 3 months. This shunt model demonstrated a gradual increase over time, with the LA continuing to enlarge up to 6 months, which more faithfully replicates the clinical situation. A major difference in the shunt model was that there was also a decrease in LV ejection fraction and an increase in LV end-systolic volume and LV end-diastolic volume similar to that seen in humans. In the chordae cut model, ventricular dysfunction was not observed. ${ }^{12,13}$ Unlike the chordae cut model, this study allowed for precise control of the degree of volume overload The placement of the occluder around the shunt not only allowed for the shunt fraction to be titrated to a set amount but also enabled complete closure, simulating MR repair.
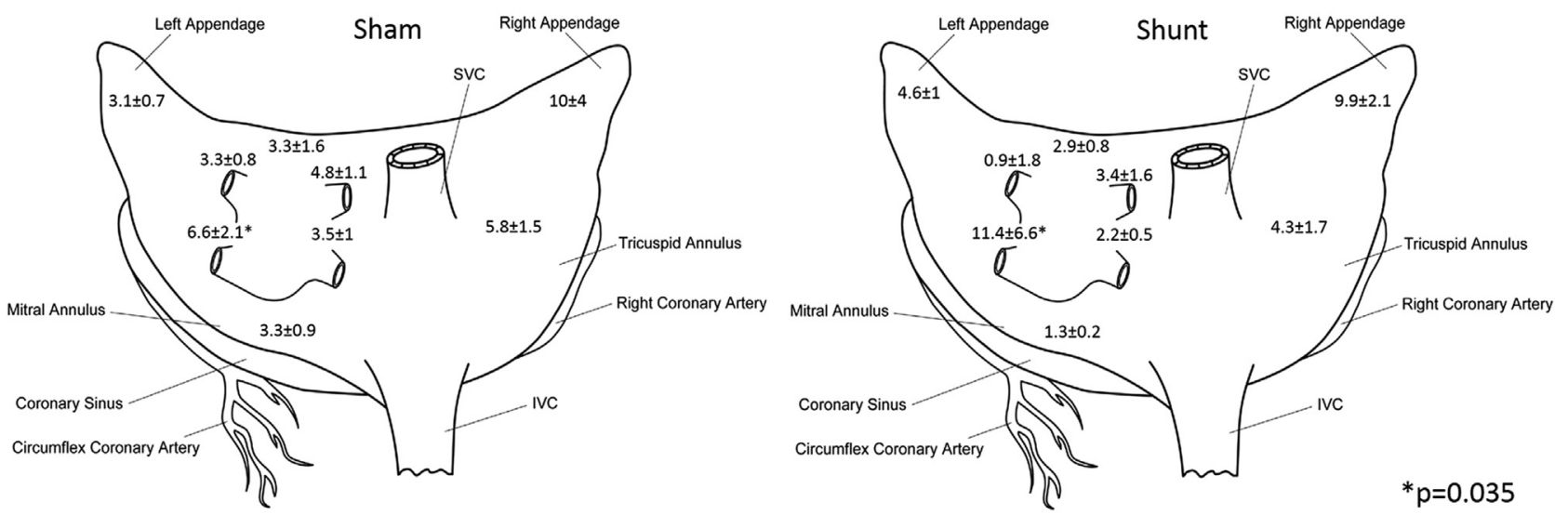

FIGURE 7. Schematic diagram of the atria showing percentage of fibrosis at the different regions biopsied. $I V C$, Inferior vena cava; $S V C$, superior vena cava. 
In this model, the AF inducibility was significantly increased. The atrial conduction times were also modestly prolonged, consistent with small but significant increase in the amount of fibrosis. Previous animal studies have also shown modest changes in conduction with MR. ${ }^{13,18,19}$ In this chronic shunt model, total activation time of the atrium increased by approximately $10 \%$ over 6 months. In the acute study, using the same shunt model, Lawrance and colleagues ${ }^{20}$ demonstrated almost exactly the same amount of increase in total activation time. In the present study, conduction was more heterogeneous in the shunt compared with the sham group in both the LA and the RA ( $P=.04$ and $P=.003$, respectively). The heterogeneity increased in the LA $(P=.02)$ from control conditions but did not increase in the sham $(P=.91)$. In a dog study in which Verheule and colleagues ${ }^{21}$ optically mapped the isolated atria, increased heterogeneity was also observed in the conduction in MR dogs compared with normal atria with premature beats. Roberts-Thomson and colleagues ${ }^{22}$ also showed that patients with MR had slower and more inhomogeneous conduction in the posterior LA compared with patients undergoing coronary artery bypass grafting.

Tang and colleagues ${ }^{13}$ and Verheule and colleagues ${ }^{21}$ reported an increase in the ERPs; however, in the present study there were no differences from baseline to 6 months in the RA or LA ERPs $(P=.92$ and $P=.30$, respectively $)$ in the shunt group. When the canine atria were isolated, Verheule and colleagues ${ }^{21}$ also reported no changes in action potential duration in the MR group. In the sham group, the ERP increased in both the LA and RA due to an unknown etiology. The combined effect of the MR and the sternotomy may have had an offsetting effect. The present study does not differentiate between the 2 effects. The net effect of this increase was that the shunt dogs had a significantly lower RAERP than the sham group $(P=.003)$. In the study by Roberts-Thomson and colleagues $^{22}$ comparing patients with MR with coronary artery bypass grafting, LAERP was longer when paced at $600 \mathrm{~ms}$, but showed no difference when paced at $400 \mathrm{~ms}$.

Normal levels of fibrosis in the LA of the dog are $1 \%$ to $2 \% .{ }^{13}$ In both the sham and shunt groups, the LA and RA were higher than these levels. The higher level of fibrosis in the sham groups suggests that the thoracotomy increased the fibrosis and is consistent with the presence of adhesions at the terminal procedure. The shunt group had a modestly higher and more inhomogeneous levels of fibrosis but was lower from $10 \%$ to $16 \%$ fibrosis reported by Tang and colleagues. ${ }^{13}$ In the shunt study, low-dose aspirin was used to prevent clotting in the shunt. Recent studies have shown that aspirin inhibits the formation of fibrosis. ${ }^{23}$ It is possible that the aspirin moderated the magnitude of fibrosis formation in the shunt animals.
None of the electrophysiologic or hemodynamic parameters (Tables 1 and 2) correlated with the total time of induced AF, but there was a high correlation with the LA volume $(\mathrm{r}=0.83, P=.002)$ and left atrial diameter $(P=.70, P=.001)$. The moderate change in conduction time and the lack of change in ERPs suggested that the dominant factor in inducibility of AF is the increased atrial size. By increasing the LA size, the animals were more likely to attain the critical mass of tissue required to support AF. $^{24,25}$ Verheule and colleagues ${ }^{12}$ also showed that the duration of AF was dependent on the degree of LA dilation.

\section{Study Limitations}

Like all other models, no spontaneous AF occurred in any animals. This is due in part because young healthy dogs are used in the study, and these dogs typically do not have spontaneous premature atrial beats. ${ }^{26}$ Another limitation is the model required a sternotomy, which has effects on some of the hemodynamic and electrophysiologic parameters (Tables 1 and 2), as well as the degree of induced fibrosis in the sham animals. The sham procedure did not affect the inducibility of AF or the overall remodeling of the atria and ventricles (Figure 4). Finally, although there were only modest changes in conduction, the resolution of these electrodes was only $5 \mathrm{~mm}$ and data were only recorded from the epicardium. Recent studies have suggested that changes in conduction are only observed at the submillimeter level. ${ }^{27}$ It is possible that small bundles of atrial myocardium, isolated by interstitial fibrosis, could have caused a unidirectional conduction block or delay facilitating AF. This would not be detectable with the electrode resolution used in the present study. Finally, multiple end points in this study were necessary to characterize the model, but this does increase the risk of type 1 error. The risk is minimized for many of the main characteristics of the model, like atrial size and LV ejection fraction, which had highly significant $P$ values.

\section{CONCLUSIONS}

This novel model of LA volume overload simulated the hemodynamic and electrophysiologic changes seen in MR including significantly increased LA volume and size, increased atrial pressure, and decreased LV ejection fraction. This model increases the vulnerability of the atria to AF by increasing LA size, inhomogeneous conduction, and fibrosis. This model allows for titratable and reversible shunt fraction, which is equivalent to the surgical repair of MV in patients with MR. Future studies using this model are planned to determine the time course of the development of the substrates for $\mathrm{AF}$ and its reversibility. The model will also be used to determine the distribution and amount of fibrosis caused by MR using delayed enhanced MRI and compare it with that observed in patients. 


\section{Conflict of Interest Statement}

R.J.D. is a speaker for AtriCure, Inc, LivaNova, Inc, CryoLife, Inc, and Edwards Lifesciences, Inc, and a consultant for Medtronic, Inc. He has received research funding and educational grants from AtriCure, Inc, and Edwards Lifesciences, Inc. All other authors have nothing to disclose with regard to commercial support.

\section{References}

1. Rahman F, Kwan GF, Benjamin EJ. Global epidemiology of atrial fibrillation. Nat Rev Cardiol. 2016;13:501.

2. Gillinov AM. Ablation of atrial fibrillation with mitral valve surgery. Curr Opin Cardiol. 2005;20:107-14.

3. Ad N, Damiano RJ Jr, Badhwar V, Calkins H, La Meir M, Nitta T, et al. Expert consensus guidelines: examining surgical ablation for atrial fibrillation. J Thorac Cardiovasc Surg. 2017; 153:1330-54.e1.

4. Gillinov AM, Gelijns AC, Parides MK, DeRose JJ Jr, Moskowitz AJ, Voisine P, et al. Surgical ablation of atrial fibrillation during mitral-valve surgery. $N$ Engl $J$ Med. 2015;372:1399-409.

5. Gaynor SL, Diodato MD, Prasad SM, Ishii Y, Schuessler RB, Bailey MS, et al. A prospective, single-center clinical trial of a modified Cox maze procedure with bipolar radiofrequency ablation. J Thorac Cardiovasc Surg. 2004;128:535-42.

6. Saint LL, Bailey MS, Prasad S, Guthrie TJ, Bell J, Moon MR, et al. Cox-Maze IV results for patients with lone atrial fibrillation versus concomitant mitral disease. Ann Thorac Surg. 2012;93:789-95.

7. Nagatsu M, Ishihara K, Zile MR, Tsutsui H, Tagawa H, DeFreyte G, et al. The effects of complete versus incomplete mitral valve repair in experimental mitral regurgitation. J Thorac Cardiovasc Surg. 1994;107:416-23.

8. Fukamachi K, Inoue M, Popovic ZB, Doi K, Schenk S, Nemeh H, et al. Off-pump mitral valve repair using the Coapsys device: a pilot study in a pacing-induced mitral regurgitation model. Ann Thorac Surg. 2004;77:688-93.

9. Rankin JS, Nicholas LM, Kouchoukos NT. Experimental mitral regurgitation: effects on left ventricular function before and after elimination of chronic regurgitation in the dog. J Thorac Cardiovasc Surg. 1975;70:478-88.

10. Carabello BA, Nakano K, Corin W, Biederman R, Spann JF Jr. Left ventricular function in experimental volume overload hypertrophy. Am J Physiol. 1989; 256(4 Pt 2):H974-81.

11. Kleaveland JP, Kussmaul WG, Vinciguerra T, Diters R, Carabello BA. Volume overload hypertrophy in a closed-chest model of mitral regurgitation. Am J Physiol. 1988;254(6 Pt 2):H1034-41.

12. Verheule S, Wilson E, Everett T IV, Shanbhag S, Golden C, Olgin J. Alterations in atrial electrophysiology and tissue structure in a canine model of chronic atrial dilatation due to mitral regurgitation. Circulation. 2003;107:2615-22.

13. Tang M, Zhang S, Sun Q, Huang C. Alterations in electrophysiology and tissue structure of the left atrial posterior wall in a canine model of atrial fibrillation caused by chronic atrial dilatation. Circ J. 2007;71:1636-42.
14. Braunwald E, Welch GH Jr, Sarnoff SJ. Hemodynamic effects of quantitatively varied experimental mitral regurgitation. Circ Res. 1957;5:539-45.

15. Lang RM, Badano LP, Mor-Avi V, Afilalo J, Armstrong A, Ernande L, et al. Recommendations for cardiac chamber quantification by echocardiography in adults: an update from the American Society of Echocardiography and the European Association of Cardiovascular Imaging. Eur Heart J Cardiovasc Imaging. 2015;16:233-70.

16. Lammers WJ, Schalij MJ, Kirchhof CJ, Allessie MA. Quantification of spatial inhomogeneity in conduction and initiation of reentrant atrial arrhythmias. Am J Physiol. 1990;259(4 Pt 2):H1254-63.

17. Kennedy DJ, Vetteth S, Periyasamy SM, Kanj M, Fedorova L, Khouri S, et al. Central role for the cardiotonic steroid marinobufagenin in the pathogenesis of experimental uremic cardiomyopathy. Hypertension. 2006;47:488-95.

18. Cox JL, Canavan TE, Schuessler RB, Cain ME, Lindsay BD, Stone C, et al The surgical treatment of atrial fibrillation. II. Intraoperative electrophysiologic mapping and description of the electrophysiologic basis of atrial flutter and atrial fibrillation. J Thorac Cardiovasc Surg. 1991;101:406-26.

19. Bloemers SM, Leurs R, Smit MJ, Verheule S, Tertoolen LG, Timmerman H et al. Mouse P19 embryonal carcinoma cells express functional histamine H1-receptors. Biochem Biophys Res Commun. 1993;191:118-25.

20. Lawrance CP, Henn MC, Miller JR, Kopek MA, Zhang AJ, Schuessler RB, et al The electrophysiologic effects of acute mitral regurgitation in a canine model. Ann Thorac Surg. 2017;103:1277-84.

21. Verheule S, Wilson E, Banthia S, Everett TH IV, Shanbhag S, Sih HJ, et al. Direction-dependent conduction abnormalities in a canine model of atrial fibrillation due to chronic atrial dilatation. Am J Physiol Heart Circ Physiol. 2004;287:H634-44.

22. Roberts-Thomson KC, Stevenson IH, Kistler PM, Haqqani HM, Goldblatt JC Sanders P, Kalman JM. Anatomically determined functional conduction delay in the posterior left atrium: relationship to structural heart disease. J Am Coll Cardiol. 2008;51:856-62.

23. Liu PP, Liu HH, Sun SH, Shi XX, Yang WC, Su GH, et al. Aspirin alleviates cardiac fibrosis in mice by inhibiting autophagy. Acta Pharmacol Sin. 2017;38: 488-97.

24. Byrd GD, Prasad SM, Ripplinger CM, Cassilly TR, Schuessler RB, Boineau JP et al. Importance of geometry and refractory period in sustaining atrial fibrillation: testing the critical mass hypothesis. Circulation. 2005;112(9 Suppl):I7-13.

25. Lee AM, Aziz A, Didesch J, Clark KL, Schuessler RB, Damiano RJ Jr. Importance of atrial surface area and refractory period in sustaining atrial fibrillation: testing the critical mass hypothesis. J Thorac Cardiovasc Surg. 2013;146:593-8.

26. Schuessler RB, Ishii Y, Khagi Y, Diabagate K, Boineau JP, Damiano RJ Jr. The effects of inflammation on heart rate and rhythm in a canine model of cardiac surgery. Heart Rhythm. 2012;9:432-9.

27. Csepe TA, Hansen BJ, Fedorov VV. Atrial fibrillation driver mechanisms: Insigh from the isolated human heart. Trends Cardiovasc Med. 2017;27:1-11.

Key Words: atrial fibrillation, mitral regurgitation 


\section{APPENDIX \\ Determination of Sample Size}

The number of dogs needed was calculated on the basis of the ability to detect a $20 \mathrm{~ms}$ change in ERP. On the basis of historic data in dogs, we used $150 \pm 10 \mathrm{~ms}$ as the control value and $130 \pm 10 \mathrm{~ms}$ as our expected value we wanted to be able to detect. The calculation was done in $\mathrm{G}^{*}$ power3.1.9.2.

Means: Difference between 2 independent means Analysis: A priori: Compute required sample size Input:

Tail $(\mathrm{s})=2$

Effect size $\mathrm{d}=2.0000000$

$\alpha$ err prob $=0.05$

Power $(1-\beta$ err prob $)=0.95$

Allocation ratio $\mathrm{N} 2 / \mathrm{N} 1=1$

\section{Output:}

Noncentrality parameter $\delta=4.0000000$

Critical $\mathrm{t}=2.1447867$

$\mathrm{Df}=14$

Sample size group $1=8$

Sample size group $2=8$

Total sample size $=16$

Actual power $=0.9602208$

The same analysis was repeated for changes in conduction time, which gave the same sample sizes. More dogs were included in the shunt group because the shunt design was still being tested and modified. As reported in the Results, there were some failures of the shunt early on, so a total of 16 dogs received implants. There were a total of 11 dogs with successful shunts, which increased the overall power of the study. 